\title{
CARACTERIZAÇÃO DA PRODUÇÃO CIENTÍFICA DOS GESTORES DE PESQUISA E DE EXTENSÃO DOS INSTITUTOS FEDERAIS
}

\author{
Magali Inês Pessini*; Luciana Calabró \\ E-mail*: magali.pessini@gmail.com \\ *Instituto Federal de Educação Ciência e Tecnologia de Santa Catarina \\ DOI: $10.15628 /$ rbept.2020.10068
}

Artigo submetido em: Maio/2020 e aceito em: Ago/2020

\begin{abstract}
RESUMO
O presente artigo objetiva caracterizar a produção científica dos Gestores de pesquisa e de extensão dos Institutos Federais. É de grande importância retratar o perfil desses gestores, que assumem o papel de zelar pelo cumprimento da missão institucional e pelas políticas e ações institucionais de pesquisa e extensão dentro de uma proposta singular de Educação Profissional e Tecnológica, que está em plena expansão e visa à consolidação de sua estrutura. Trata-se de uma pesquisa descritiva, de abordagem quantitativa. Esta investigação se pautou pela análise do cenário institucional, pelas características do perfil dos gestores, tais como: gênero, instituição de doutoramento e função institucional. Traçamos um percurso metodológico alicerçado no conceito de Cientometria e constatamos que, com titulação acadêmica mais elevada, os gestores de pesquisa possuem produção científica maior do que os gestores de extensão.
\end{abstract}

Palavras-chave: Gestores. Pesquisa. Extensão. Institutos Federais. Produção Científica.

\section{CHARACTERIZATION OF THE SCIENTIFIC PRODUCTION OF THE RESEARCH AND EXTENSION MANAGERS OF THE FEDERAL INSTITUTES}

\begin{abstract}
This article aimed to characterize the scientific production of research and extension Managers at Federal Institutes. We present the concepts of Research, Extension, Management and Scientometrics. It is of great importance to portray the profile of these managers who assume the role of ensuring the fulfillment of the institutional mission and the institutional research and extension policies and actions within a unique proposal of Professional and Technological Education, which is in full expansion and aims at consolidating structure and expansion of the scientific knowledge produced by it. It is a descriptive research, with a quantitative approach. This investigation was based on the analysis of the institutional scenario, the characteristics of the profile of managers such as: gender, doctoral institution and institutional function. We traced a methodological path based on the concept of Scientometry, and we found that with higher academic degrees, research managers have greater scientific production than extension managers.
\end{abstract}

Keywords: Managers. Research. Extension. Federal Institutes. Scientific Production. 


\section{INTRODUÇÃO}

Em conjunto com as políticas e os processos de expansão das universidades federais, o Ministério da Educação (MEC) anunciou o lançamento do Plano de Desenvolvimento da Educação - PDE (BRASIL, 2007), que tem como objetivo principal a reestruturação da Rede Federal de Educação. A ação foi coordenada e executada pela Secretaria de Educação Profissional e Tecnológica (SETEC) do MEC e resultou na criação dos Institutos Federais de Educação. Em 29 de dezembro de 2008, foi sancionada a Lei 11.892, que dispõe da criação dos Institutos Federais, os quais selaram o compromisso de orientar suas ações a partir dos princípios da indissociabilidade entre ensino-pesquisa-extensão (BRASIL, 2008). Sendo assim, o ensino, a pesquisa e a extensão formam o tripé de apoio nos processos de ensino e aprendizagem dos Institutos Federais.

Os Institutos Federais de Educação Ciência e Tecnologia foram criados pela Lei oㅜ 11.892, de 29 de dezembro de 2008, que "institui a Rede Federal de Educação Profissional, Científica e Tecnológica, cria os Institutos Federais de Educação Ciência e Tecnologia e dá outras providências" (BRASIL, 2008). A partir dessa lei, os CEFETs, as Escolas Agrotécnicas Federais (EAFs) e algumas escolas vinculadas às universidades passaram a formar os Institutos Federais.

O modelo institucional dos Institutos Federais é inovador em termos de proposta político-pedagógica. $\mathrm{Na}$ base dessas instituições está um conceito de educação profissional e tecnológica, uma organização pedagógica verticalizada, da educação básica à superior. Ela permite que os professores atuem em diferentes níveis de ensino e que os alunos compartilhem os espaços de aprendizagem, incluindo os laboratórios, possibilitando 0 delineamento de trajetórias de formação. Assim, na missão dessas instituições está o compromisso de intervenção em suas respectivas regiões, identificando problemas e criando soluções técnicas e tecnológicas para o desenvolvimento sustentável com inclusão social. Buscando sintonia com as potencialidades de desenvolvimento regional, os cursos, nas novas unidades, devem ser definidos através de audiências públicas e de escuta junto a representações da sociedade.

Os Institutos Federais também possuem como proposta realizar e estimular a pesquisa aplicada, a produção cultural, o empreendedorismo, o cooperativismo, além de promover a produção, o desenvolvimento e a transferência de tecnologias sociais. Devem, ainda, orientar sua oferta formativa em benefício da consolidação e do fortalecimento dos arranjos produtivos, sociais e culturais locais, a partir do mapeamento das 
potencialidades de desenvolvimento socioeconômico e cultural em cada Instituto Federal (BRASIL, 2008).Com a sua estrutura multicampi e capilaridade nos territórios, a gestão de pesquisa e de extensão dos Institutos Federais, é diversa, múltipla e dia após dia, passa por mudanças no que tange os servidores que gerem tais funções, bem como na estruturação de inúmeros organogramas e normativas institucionais. Diante desta realidade volátil, dos pressupostos legais e de organização de cada instituição, a problemática deste estudo pautou-se na seguinte questão: Qual é o perfil e a produção científica dos gestores de pesquisa e de extensão dos Institutos Federais?

E, nesta perspectiva, nosso estudo se faz importante para caracterizar a produção científica dos gestores de pesquisa e de extensão dos Institutos Federais, e não só servir para apontar subsídios para as gestões das instituições, mas para fortalecer as práticas de produção e divulgação de produções científicas realizados nos e pelos Institutos Federais, bem como conhecer o perfil dos gestores de pesquisa e de extensão, que em suas unidades organizacionais fomentam e, muitas vezes realizam ações de pesquisa e de extensão.

O objetivo deste estudo é caracterizar quantitativamente a produção científica dos gestores de pesquisa e de extensão dos Institutos Federais. A pesquisa desenvolvida é de natureza aplicada e de abordagem descritiva. Neste artigo, é apresentado o mapeamento das publicações científicas dos gestores de pesquisa e de extensão de todos os Institutos Federais (38) do território nacional, totalizando 1126 gestores, sendo 563 gestores de Pesquisa e 563 gestores de Extensão.

O referencial teórico utilizado para construção desse estudo, funda-se no seu objetivo de estudo e cenário de pesquisa. Sendo que, para caracterizar "Extensão" faz-se uso da abordagem conceitual da Política Nacional de Extensão Universitária proposta pelo FORPROEX (2012). Já para conceituar "Pesquisa" o aporte usado nas publicações alicerça-se em Galiazzi et al. (2001) e Demo (1997).

Quanto estratégica metodológica adotada na pesquisa, optamos por desenvolver um estudo de cunho descritivo, fazendo uso do conceito de Gil (2002). No tratamento dos dados, cuja análise tange produção científica utilizamos a Cientometria, seguindo os conceitos de Meadows (1999), Berti et al. (2010) e Jacobs (2010). 


\title{
2 PESQUISA E EXTENSÃO
}

\subsection{PESQUISA}

O conceito de pesquisa de Barros e Lehfeld (1986) a retrata como um ato dinâmico de questionamento, indagação e aprofundamento consciente, na tentativa de buscar conhecimento sobre determinados objetos. Para realizar pesquisa, é necessária uma busca incessante por uma resposta a uma dúvida ou a um problema. Os autores ainda destacam que pesquisar é um fato natural e necessário a todas as pessoas:

\begin{abstract}
A pesquisa é uma atividade comum, não só entre os cientistas, mas para todos os indivíduos atuantes na sociedade. O professor, o aluno, ou um consumidor podem, dentro de uma área de ação, tomar a pesquisa como instrumento para estudo e análise dos pontos negativos ou positivos de um problema. (BARROS; LEHFELD, 1986, p. 58).
\end{abstract}

Para completar o conceito, Demo (1997, p. 9) destaca que o cerne da pesquisa é desenvolver habilidades "indispensáveis em cada cidadão e trabalhador modernos: aprender a aprender e saber pensar para intervir de modo inovador". O autor também reflete sobre a pesquisa como condição básica "por seu lado educativo emancipatório, sua marca de atitude cotidiana, sua viabilidade em qualquer pessoa, sua relação intrínseca com 0 conhecimento inovador" (DEMO, 1997, p. 53). Assim, a pesquisa, tanto a básica quanto a aplicada, precisa, ao lado do ensino e da extensão, constituir-se como uma atividade progressivamente constante nos meios acadêmicos e nas atividades de difusão de conhecimento e de intervenção em problemas efetivos da sociedade.

Nesse sentido, Maria do Carmo Galiazzi e colaboradores (2001, p. 4748) afirmam:

A pesquisa não é o único caminho para o desenvolvimento profissional, mas é essencial para a construção da competência em qualquer prática profissional. [...]. Em síntese, o sujeito que usa a pesquisa como processo de formação permanente desenvolve a capacidade investigativa, a autonomia e a criatividade.

A partir dos conceitos de pesquisa aqui apresentados, identifica-se que: estudo, investigação e indagação são termos frequentes com que se conceitua pesquisa. Observa-se ainda que os autores citados afirmam que a 
pesquisa tem uma finalidade: a de elaborar conhecimentos que permitam facilitar a compreensão dos problemas levantados pela sociedade e, por conseguinte, fortalecer a ação transformadora dos processos socioeducacionais.

Os Institutos Federais possuem a missão de desenvolver ciência e tecnologia. $\mathrm{E}$, interligando saberes tecnológicos, culturais e científicos, a pesquisa desenvolvida nos e pelos Institutos Federais se fortalece na produção do conhecimento enquanto inovação e também enquanto formação. Assim, o perfil institucional dos Institutos Federais caminha para a consolidação de uma prática de produção e de difusão do saber (KUNZE; CONCIANI, 2007).

\subsection{EXTENSÃO}

No Brasil, o termo extensão aparece no Estatuto das Universidades Brasileiras (Decreto $n^{\circ} 19.851,11 / 04 / 31$ ), em seu artigo 35ํㅡ, que prevê, em institutos de ensino profissional superior, a realização de "cursos de extensão universitária, destinados a prolongar, em benefício coletivo, a atividade técnica e científica dos institutos universitários" (BRASIL, 1931). O trecho do documento da XXVIII Reunião Plenária do Conselho de Reitores das Universidades Brasileiras (CRUB), realizada em 1979, afirma que: "[d]ecorre da extensão o conhecimento da realidade, a formação de consciência crítica e enriquecimento curricular, beneficiando o corpo docente, discente e administrativo". (MORAES FILHO; SILVEIRA, 2011, p. 5).

Em 1987, cria-se o FORPROEX, Fórum de Pró-Reitoras e PróReitores de Extensão das Instituições Públicas de Educação Superior Brasileiras, que assume um papel importante, porque conceitua a extensão da forma como ainda hoje é assumida:

\footnotetext{
A extensão é uma via de mão-dupla, com trânsito assegurado à comunidade acadêmica, que encontrará, na sociedade, a oportunidade de elaboração da práxis de um conhecimento acadêmico. No retorno à universidade, docentes e discentes trarão um aprendizado que, submetido à reflexão teórica, será acrescido àquele conhecimento. (NOGUEIRA, 2000, p. 11-12).
}

A Política Nacional de Extensão Universitária, por sua vez, discorre que a extensão deve ser um "instrumento de mudança social em direção à justiça, à solidariedade e à democracia" (FORPROEX, 2012, p. 4). A busca 
de relevância para o conhecimento produzido e compartilhado pela instituição de educação superior aporta com segurança nas atividades de extensão.

A extensão feita nos Institutos Federais é, na realidade, uma forma de interação que deve existir entre a instituição e a comunidade na qual está inserida. É uma espécie de ponte permanente entre a instituição e os diversos setores da sociedade. Funciona como uma via de duas mãos, em que a instituição de ensino, no caso os Institutos Federais de Educação Ciência e Tecnologia, através de seus programas e projetos, leva conhecimentos e/ou assistência à comunidade, e recebe dela influxos positivos como retroalimentação, tais como suas reais necessidades, seus anseios e aspirações. Ocorre, na realidade, uma troca de conhecimentos, em que o Instituto também aprende com a própria comunidade sobre seus valores e sua cultura. Assim, o Instituto, como ente público e voltado para contribuir para os processos de ensino, pesquisa e extensão, pode planejar e executar as atividades de extensão respeitando, e não violando, esses valores e culturas locais e regionais_(MEC, 2010).

O Instituto Federal aponta para um novo tipo de instituição, identificada e comprometida com o projeto de sociedade em curso no país. Representa um salto qualitativo em uma caminhada singular; trata-se, portanto, de uma estratégia de ação política e de transformação social (BRASIL, 2008). Os Institutos Federais, como política de Estado, acabam assumindo a função de agentes colaboradores, muitas vezes corroborando a implantação e execução de políticas públicas na região em que são polos educacionais. Assim, "tratase, portanto, de um espaço aberto e em movimento, de atuação regional, com bases em referenciais que expressam sua missão". (BRASIL, 2008).

É compromisso de cada Instituto Federal conhecer a região em que está inserido e responder efetivamente aos anseios e demandas da comunidade, sendo instrumento em prol da inclusão social e melhor distribuição de renda. Com base nessa concepção de ofertar de uma educação que atenda os arranjos produtivos locais que os Institutos Federais, enquanto instituições de educação profissional, científica e tecnológica, têm como princípio norteador de suas ações o desenvolvimento local e regional, em articulação com o contexto em que estão inseridos. Alicerçado no diálogo entre instituição e comunidade, cada Instituto amplia seu campo de atuação ao espaço do território geográfico no qual está inserido e passa a ser o campo de negociação em prol da construção de uma rede de parceria (MEC, 2010). 


\section{GESTÃO NOS INSTITUTOS FEDERAIS}

A Lei o. 11.892, de 29 de dezembro de 2008, em suas premissas, determina, no caput dos seus artigos $9^{\circ}$ e $11^{\circ}$, que:

[...] cada Instituto Federal é organizado em estrutura multicampi, com proposta orçamentária anual identificada para cada campus e a reitoria, exceto no que diz respeito a pessoal, encargos sociais e benefícios aos servidores. [...] Os Institutos Federais terão como órgão executivo a reitoria, composta por 1 (um) reitor e 5 (cinco) pró-reitores. (BRASIL, 2008)

O formato singular e único dos Institutos Federais com relação às outras instituições de educação no Brasil, em relação a sua atuação nas diferentes modalidades de educação do país e ao tripé ensino-pesquisaextensão, além de sua estrutura multicampi e pluricurricular, se propõe a uma nova institucionalidade e, dessa forma, necessita de novos procedimentos de gestão.

Nesse sentido, aos seus gestores competem as funções de definição de políticas, supervisão e controle institucional. Sendo assim, a estrutura dos Institutos Federais abrange as cinco pró-reitorias previstas na legislação, nas quais as atribuições são solicitadas para as principais áreas de funcionamento da instituição. São elas: acadêmica (denominação própria em função da especificidade da oferta verticalizada de ensino, que vai da educação continuada à pós-graduação, conexa com a pesquisa e a extensão em todo o trajeto da formação acadêmica); de pesquisa e inovação; de extensão e integração instituição-sociedade; de desenvolvimento institucional; e de planejamento e administração (FERNANDES, 2009).

Por sua vez, os campi, enquanto unidades organizacionais de execução da ação educacional, possuem diversas dimensões e peculiaridades, estão espalhados por todo o país e são de variados tamanhos e estruturas administrativas, em função dos quantitativos de cargos de direção e de funções gratificadas disponíveis para cada Instituto Federal. Congregam regimentos próprios que determinam suas políticas e ações institucionais (FERNANDES, 2009).

\section{CIENTOMETRIA}

Conforme apontam Santos e Kobashi (2009), o mapeamento da ciência vem se estabelecendo como uma forte tendência que tem o intuito de 
aprofundar os debates acerca da dinâmica da ciência e de sua comunicação, possibilitando, desse modo, que aspectos cognitivos ultrapassem as análises quantitativas, sendo que a quantificação do volume de produções científicas, por meio de estudos cientométricos, vem ganhando força nas últimas décadas. Para que tais indicadores e estudos se fortaleçam, torna-se imprescindível a divulgação dos resultados de pesquisas através de livros, capítulos de livros, artigos científicos, dissertações, teses e eventos científicos, que são de fundamental relevância na avaliação da atividade científica (OKUBO, 1997).

A Cientometria é considerada o estudo dos aspectos quantitativos da ciência enquanto disciplina ou atividade econômica. Além disso, integra a Sociologia da Ciência, e sua aplicação dá-se na formulação de políticas científicas. Envolve estudos quantitativos de atividades científicas, incluindo, entre outros, a publicação científica (JACOBS, 2010).

É possível, por meio da Cientometria, desenvolver indicadores com o objetivo de avaliar a produção científica dos indivíduos, grupos, instituições, das áreas do conhecimento e países. Esses indicadores da atividade científica estão no centro dos debates e se constituem como elementos essenciais para o desenvolvimento de políticas públicas (BERTI et al., 2010). Diante do exposto, este estudo decorre da relevância de se caracterizar a produção científica dos gestores de pesquisa, inovação e pós-graduação e de extensão dos Institutos Federais, pois estes gestores pelas políticas e ações institucionais de pesquisa e extensão de acordo com uma proposta singular de Educação Profissional e Tecnológica.

\section{PROCEDIMENTOS METODOLÓGICOS}

Para a realização da investigação, optou-se por desenvolver um estudo descritivo de abordagem quantitativa. Gil (2002) destaca que a pesquisa descritiva tem como objetivo descrever as características de determinadas populações ou fenômenos, com utilização de técnicas padronizadas de coleta de dados, ou seja, de questionário e de observação sistemática. Neste estudo, a pesquisa descritiva apresenta características do grupo de gestores de pesquisa e extensão, tendo como cenário de pesquisa os 38 Institutos Federais, seus 643 campi, e destes 1126 gestores, sendo 563 gestores de Pesquisa e 563 gestores de Extensão. 
Figura 1: Mapa dos campi dos Institutos Federais

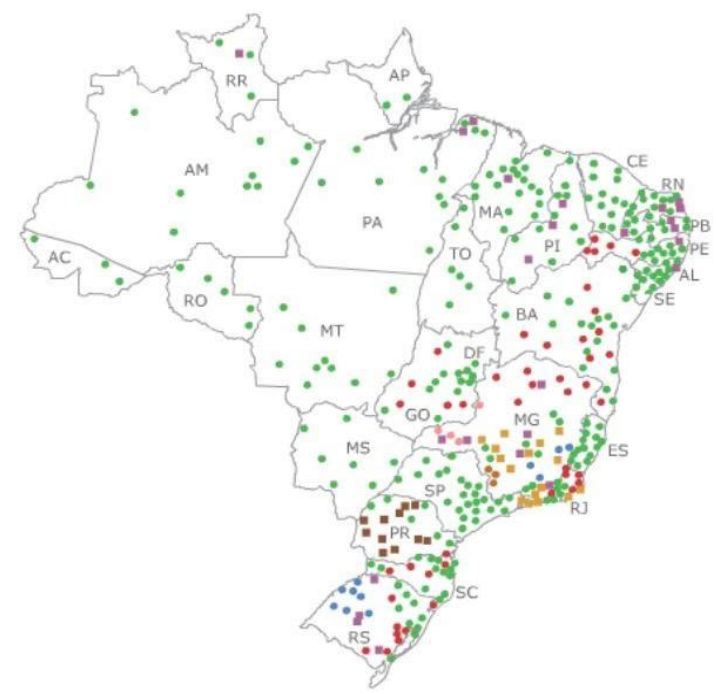

Fonte: Rede Federal de Educação Profissional, Científica e Tecnológica (2016)

A análise de produções científicas dos gestores de pesquisa e de extensão, em cada unidade dos Institutos Federais, se deu pela quantificação das publicações. Considerou-se também o perfil (gênero, área de formação e titulação) de cada um desses gestores. Optou-se por denominar o grupo populacional analisado de gestores, pois, como os Institutos Federais são instituições multicampi, entre as unidades organizacionais, e conforme regimentos próprios de cada campus, existem denominações diferentes para esses. Em algumas unidades, são chamados de diretores(as) e em outras de coordenadores(as), devido ao organograma regimental construído por cada comunidade institucional, que tem como base a realidade em que está inserida.

Foram analisados todos os currículos cadastrados na Plataforma Lattes do CNPq dos gestores de pesquisa e de extensão, e se buscou quantificar e identificar a produção científica de cada um dos gestores. Também foram extraídas informações do perfil de cada um dos gestores: gênero, área de formação e titulação, além do número de documentos (artigos científicos; capítulos de livros, livros; resumos completos, expandidos; trabalhos completos em anais e resumos publicados em anais). Cabe salientar que os pró-reitores de pesquisa e de extensão, bem como seus adjuntos, não fazem parte do mapeamento realizado neste estudo. A coleta de dados se deu entre os dias 7 e 12 do mês de dezembro de 2019.

Os dados foram organizados e analisados utilizando o software Excel. Os dados foram tabulados e as produções divididas em categorias, sendo elas: artigos científicos; capítulos de livros, livros; resumos, expandidos/completos; e resumos. . 
Cabe relatar que nossa dificuldade na construção do cenário nacional são as mudanças pelas quais as gestões de Pesquisa e de Extensão passam. Por isso, para dirimirmos tal dificuldade na coleta de dados, determinamos um prazo, pois entendemos que os Institutos Federais se constituem enquanto autarquias vivas e dinâmicas.

\section{RESULTADOS}

Quanto ao perfil dos gestores de pesquisa e extensão dos Institutos Federais, temos:

QUADRO 1: Perfil dos gestores de pesquisa e de extensão dos Institutos Federais

\begin{tabular}{|c|c|c|c|c|}
\hline Gestores & \multirow{2}{*}{\multicolumn{2}{|c|}{$\begin{array}{c}\text { Pesquisa } \\
54,35 \%\end{array}$}} & \multicolumn{2}{|c|}{ Extensão } \\
\hline Doutores & & & \multicolumn{2}{|c|}{$32,14 \%$} \\
\hline Mestres & \multicolumn{2}{|c|}{$37,30 \%$} & \multicolumn{2}{|c|}{$45,29 \%$} \\
\hline Especialistas & \multicolumn{2}{|c|}{$6,21 \%$} & \multicolumn{2}{|c|}{$17,22 \%$} \\
\hline Graduados & \multicolumn{2}{|c|}{$2,13 \%$} & & \\
\hline \multirow[t]{2}{*}{ Gênero } & Feminino (\%) & Masculino (\%) & Feminino (\%) & Masculino (\%) \\
\hline & 29,66 & 70,33 & 38,36 & 61,63 \\
\hline \multicolumn{5}{|c|}{ Ingresso na Instituição } \\
\hline $\begin{array}{c}\text { Anterior a } \\
2008\end{array}$ & \multicolumn{2}{|c|}{$16,87 \%$} & \multicolumn{2}{|c|}{$15,80 \%$} \\
\hline Após 2008 & \multicolumn{2}{|c|}{$83,12 \%$} & \multicolumn{2}{|c|}{$84,19 \%$} \\
\hline
\end{tabular}

Do total de gestores de pesquisa, 527 são docentes e 53 são técnicosadministrativos em Educação. Já do total de gestores de extensão, 457 são docentes em Educação e 106 são técnicos-administrativos.

A expansão da Rede Federal foi responsável pela implantação e pela consolidação de 643 campi dos Institutos Federais em todo o país (REDE FEDERAL, 2016), o que demandou a ampliação da oferta de educação profissional em diferentes áreas do conhecimento e modalidades. Essa demanda então requereu a contratação de novos servidores. É expressiva a quantidade de doutores no quadro de gestores de pesquisa, indicador que a Rede tem perseguido por meio de programas de capacitação. Cabe aqui frisar que não se pode exigir o título de doutorado nos concursos públicos para a carreira de professores do Ensino Básico, Técnico e Tecnológico (EBTT), nem em certames de contratação de técnicos-administrativos em Educação.

A alta qualificação dos servidores/gestores de pesquisa e de extensão se alicerçam na efetivação dos pressupostos da Política Nacional de Desenvolvimento de Pessoal, criada pelo Decreto n. 5.707, de 23 de fevereiro 
de 2006, que tem por finalidade melhorar a eficiência, a eficácia e a qualidade dos serviços prestados ao cidadão, proporcionar o desenvolvimento permanente do serviço público, adequar as competências requeridas dos servidores aos objetivos das instituições e racionalizar, por economicidade, os gastos públicos (BRASIL, 2006). Os Institutos Federais, com base na política de desenvolvimento de pessoal, fomentam inúmeras ações de incentivo à capacitação e à qualificação de seus servidores em diversos níveis e modalidades de formação. Esses programas objetivam incentivar os servidores em iniciativas que desenvolvam competências inerentes às suas atribuições e funções, fomentando a participação em ações de formação.

Sobre a área de formação inicial dos gestores de pesquisa e de extensão analisados, formulamos o seguinte cenário:

Quadro 2: área de formação inicial dos gestores de pesquisa e de extensão dos Institutos Federais

\begin{tabular}{|c|c|c|}
\hline Áreas de formação inicial & Gestores de Pesquisa & Gestores de Extensão \\
\hline Ciências Agrárias & 92 & 84 \\
\hline Ciências Biológicas & 41 & 31 \\
\hline Ciências da Saúde & 28 & 30 \\
\hline Ciências Exatas e da Terra & 89 & 63 \\
\hline Engenharias & 128 & 103 \\
\hline Ciências Humanas & 79 & 115 \\
\hline Ciências Sociais Aplicadas & 54 & 56 \\
\hline Linguística, Letras e Artes & 46 & 80 \\
\hline
\end{tabular}

Conforme observado no Quadro 2, a área de conhecimento de maior formação dos gestores de extensão é a área das Ciências Humanas. Já nos gestores de pesquisa são as Engenharias, seguida pela área das Ciências Agrárias. A menor área de formação dos dois grupos de gestores é a área das Ciências da Saúde. Em se tratando da área de Linguística, Letras e Artes, o quantitativo de gestores de extensão com formação inicial nesta área é quase o dobro que os gestores de pesquisa.

Pode-se considerar que a produção científica é composta não somente pela realização de uma pesquisa científica, mas também pela divulgação dos resultados dessa pesquisa. A importância do processo de divulgação dos resultados obtidos é fundamental para que o conhecimento científico adquira confiabilidade e para que os seus autores tenham credibilidade e prestígio. É através da divulgação dos seus resultados que essa deixa de ser uma atividade privada e se torna uma atividade social (TARGINO; GARCIA, 2000).

Referente às publicações científicas se obteve o seguinte cenário: 
Figura 2: Produção científica dos gestores de pesquisa e de extensão dos Institutos Federais

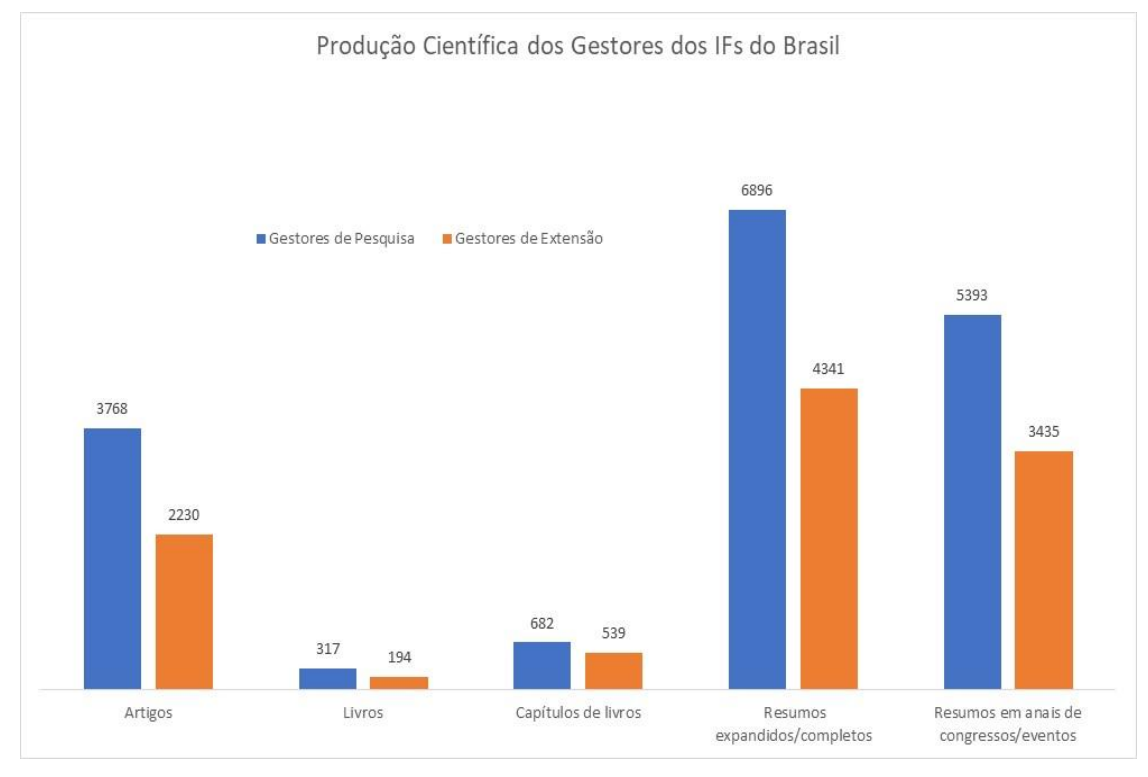

Em relação às produções científicas, os gestores de pesquisa publicaram 3.768 artigos científicos. Já os gestores de extensão publicaram 2.230 artigos científicos.

Quanto à publicação de capítulos de livros, os gestores de pesquisa somam um quantitativo de publicações de 682, já os gestores de extensão, 539 capítulos publicados. Nos livros publicados, os gestores de extensão possuem juntos 194 livros publicados; já os gestores de pesquisa totalizam 317 livros publicados. Tais informações também são observadas quando analisadas as publicações de resumos expandidos/completos: os gestores de pesquisa contabilizam um total de 6.896, e os gestores de extensão, 4.341. No que se refere aos resumos, os gestores de pesquisa somam 5.393 publicações, e os gestores de extensão 3.435 .

\subsection{PRODUÇÃO CIENTÍFICA DOS GESTORES DE PESQUISA E DE EXTENSÃO POR REGIÃO DO BRASIL}

\subsubsection{Região Sul}

Na região, foram analisados 87 gestores de pesquisa e de extensão. 
Figura 3: Produção científica dos gestores de pesquisa e de extensão da Região Sul

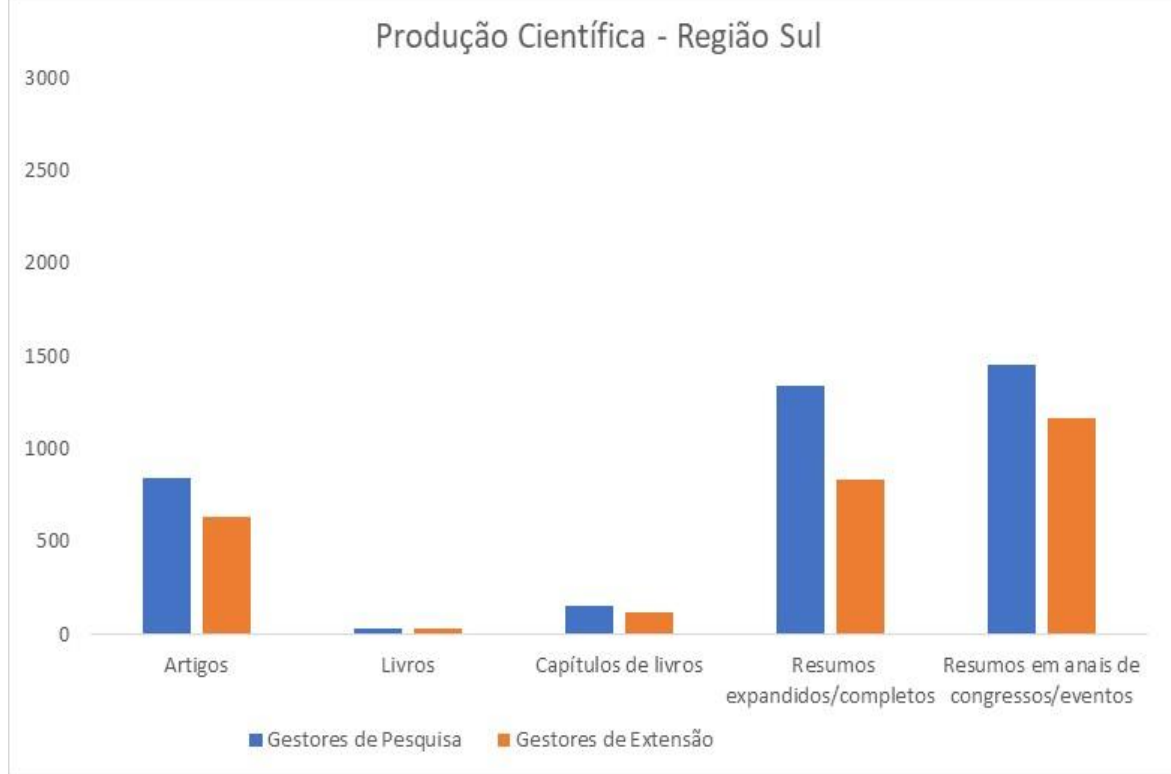

\subsubsection{Região Sudeste}

Já na região Sudeste foram analisados 144 gestores no total. 
Figura 4: Produção científica dos gestores de pesquisa e de extensão da Região Sudeste

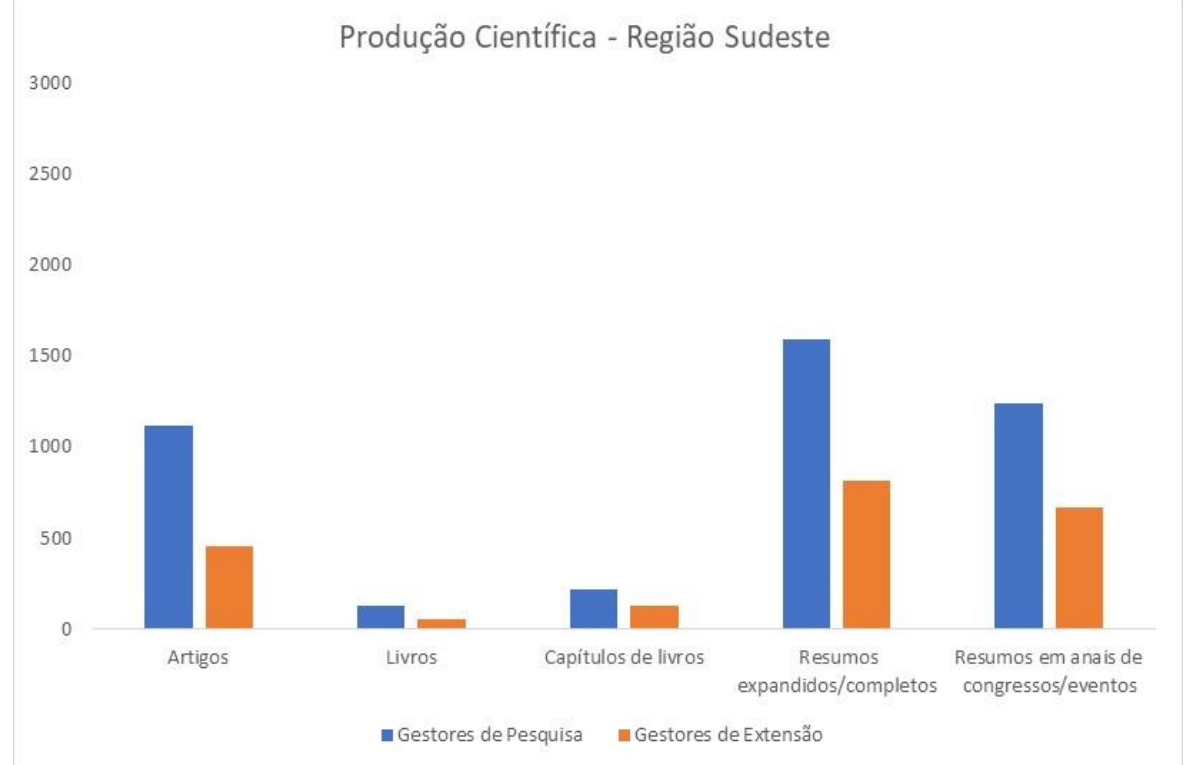

\subsubsection{Região Norte}

$\mathrm{Na}$ região Norte, 65 gestores de pesquisa e de extensão foram analisados. 
Figura 5: Produção científica dos gestores de pesquisa e de extensão da Região Norte

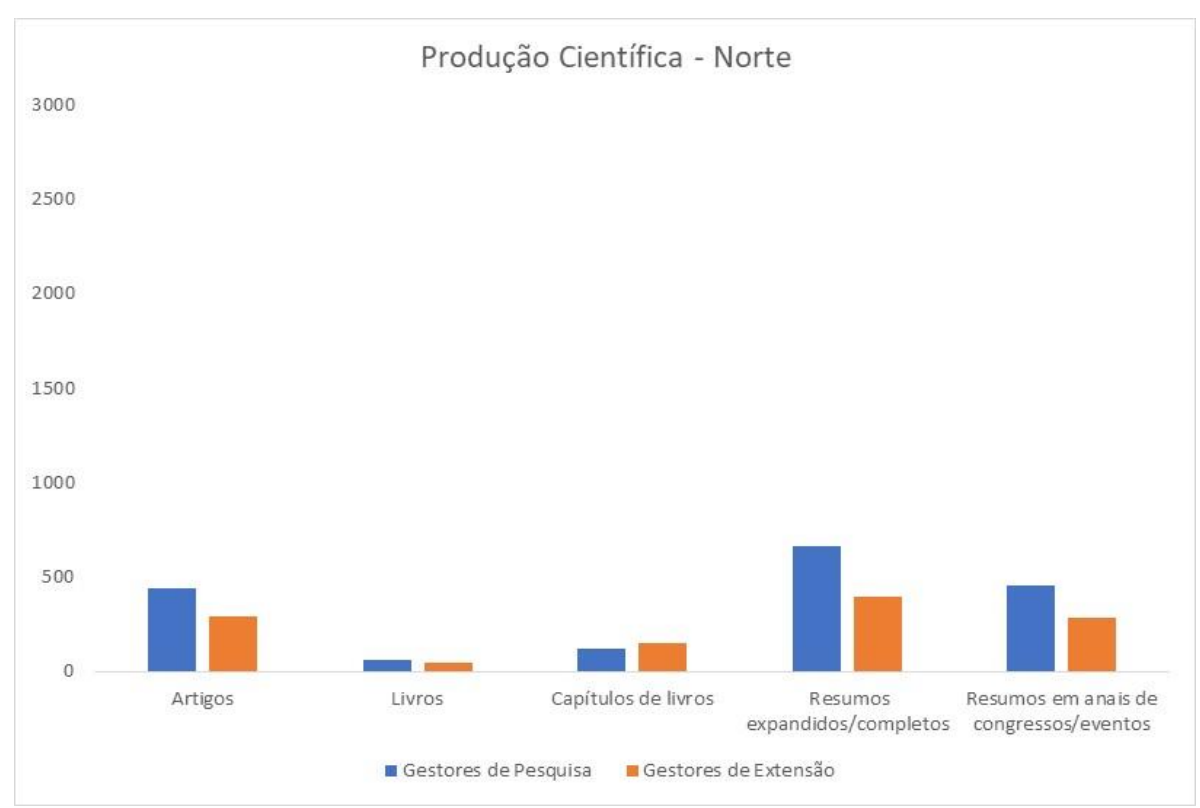

\subsubsection{Região Nordeste}

O total de gestores analisados na região Nordeste foi de 202.

Figura 6: Produção científica dos gestores de pesquisa e de extensão da Região Nordeste

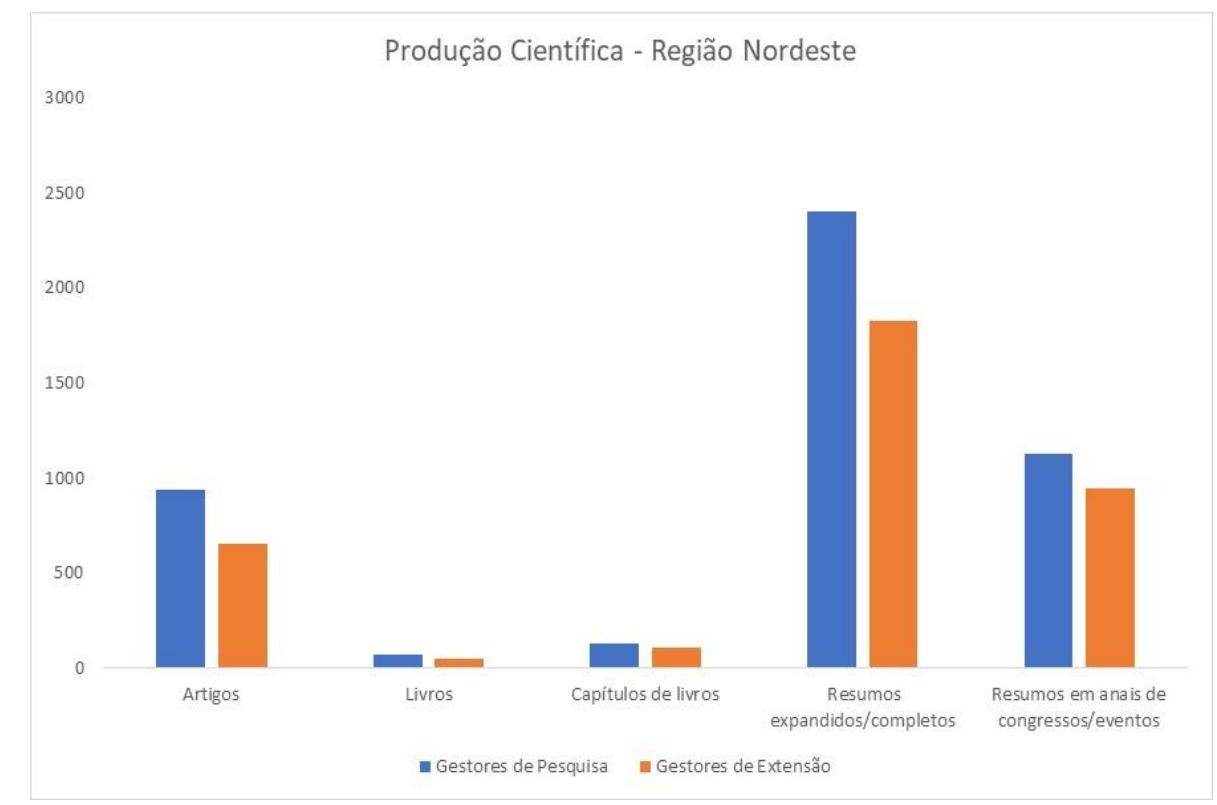




\subsubsection{Região Centro-Oeste}

E na região Centro-Oeste, o quantitativo de gestores analisados foi de 65.

Figura 7: Produção científica dos gestores de pesquisa e de extensão da Região CentroOeste

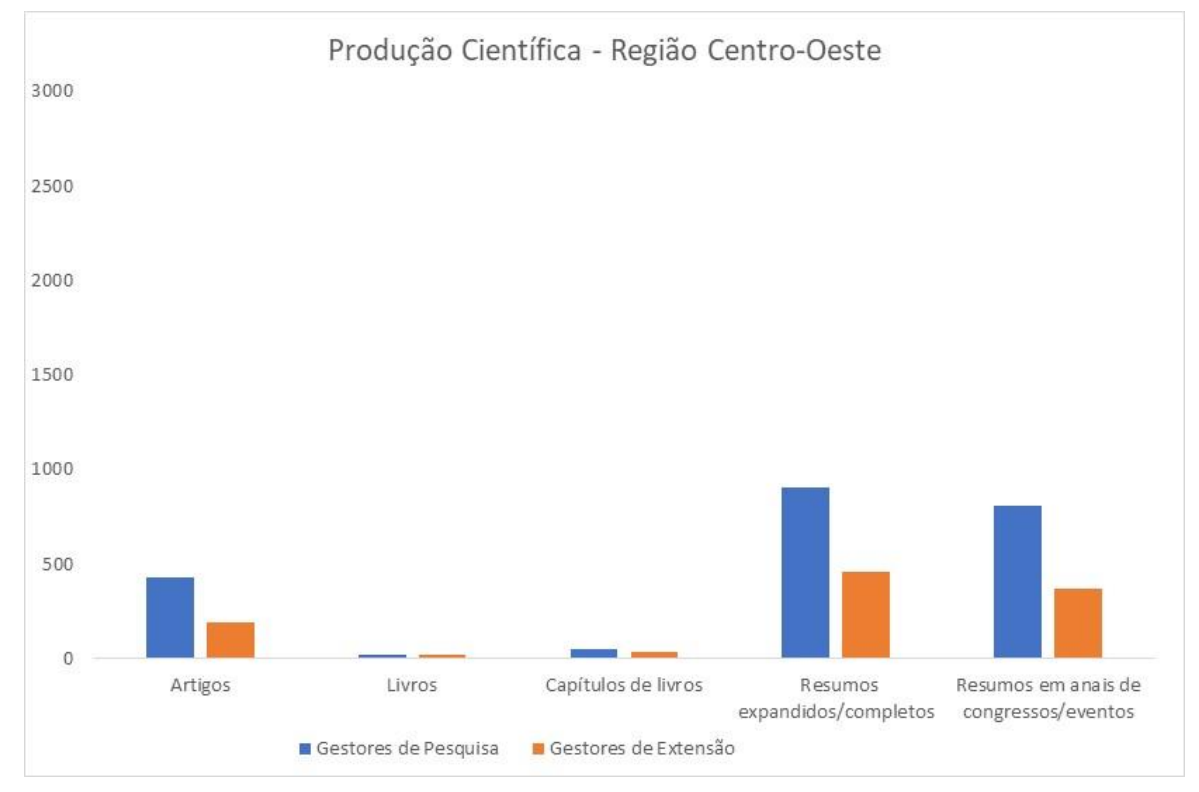

Sabemos que os quantitativos de publicações e de revistas científicas são indicadores favoráveis à abertura de novos programas de pós-graduação stricto sensu, pois os critérios adotados pelos Conselhos Técnico-Científicos (CTC) da Capes evidenciam a produção científica dos docentes que constituem as propostas de cursos submetidas à avaliação. Vale ressaltar aqui que os CTC/Capes não consideram apenas o resultado quantitativo do número de publicações, mas também a relevância dos periódicos nos quais os artigos são publicados. Neste estudo, não categorizamos as publicações conforme sua qualificação, devido às peculiaridades de cada área de conhecimento.

Analisados os dados separadamente por região do Brasil, os gestores de pesquisa ainda possuem uma maior produção científica que os gestores de extensão, porém, na região Norte, se observou que os gestores de extensão possuem um maior quantitativo de livros publicados em detrimento dos gestores de pesquisa, o que, por sua vez, não é observado em nenhum outro cenário analisado. 
A análise regional da produção científica dos gestores de pesquisa e de extensão dos Institutos Federais evidencia a acentuada heterogeneidade espacial da produção científica, com enorme concentração nas regiões Sudeste e Sul. Assim, reiteramos que a formação de recursos humanos e a produção científica dependem em grande parte do investimento de recursos públicos. A formação de mestres e doutores mais produtivos equivale a investir melhor os recursos públicos. (PACHECO; KERN, 2001). Também se faz necessária, a democratização e o direcionamento da ciência e tecnologia para $o$ atendimento das demandas locais, contribuindo para o enfrentamento das desigualdades regionais e sociais do país.

\section{CONSIDERAÇÕES FINAIS}

Metodologicamente, a pesquisa cientométrica que realizamos nos possibilitou caracterizar a produção científica dos gestores de Pesquisa e de Extensão dos 38 Institutos Federais, que se constituem enquanto territórios de abrangências distintas, seja em número de campi ou número de servidores, ou até mesmo de alunos. Cada um destes ainda possui autonomia para propor sua estrutura organizacional de atuação, e implantar suas políticas próprias de pesquisa e de extensão.

Do ponto de vista da caracterização da produção científica dos gestores de pesquisa e de extensão, a produção dos gestores de pesquisa é maior que a produção científica dos gestores de extensão. Verificamos que os gestores de pesquisa são, em maior número, doutores e docentes. Tal constatação está atrelada à diferença da titulação exigida para o ingresso docente na Rede Federal de Educação Profissional e Tecnológica e para o ingresso de técnicos-administrativos na Rede. Ainda, por descrição legal de atribuições e funções, estes, por sua vez, desempenham funções de apoio e assistência aos gestores docentes. Pois, em comparação, temos mais servidores técnicos-administrativos como gestores de extensão do que técnicos-administrativos exercendo a gestão de pesquisa.

Os resultados obtidos, além de retratar o perfil dos gestores e comparar sua produção científica, evidencia que os gestores de pesquisa possuem maior titulação que os gestores de extensão e, por conseguinte, que o número de publicações dos gestores de pesquisa é maior que os de extensão. Dados como esses podem levar à ideia de que os gestores de pesquisa já estão habituados com o "fazer pesquisa" e com a publicação de seus feitos no decorrer suas trajetórias acadêmicas, visto que mais da metade $(54,35 \%)$ destes gestores são doutores. Os principais resultados que obtivemos dizem respeito às características das publicações científicas dos gestores de pesquisa e de extensão dos Institutos Federais. Com métodos 
cientométricos, analisamos a produção científica desses gestores, considerando informações do perfil pessoal e o contexto institucional em que estão inseridos.

Nesse cenário de pesquisa, com instituições centenárias e outras com pouco tempo de criação, pudemos conhecer os gestores que fomentam a pesquisa e a extensão nas unidades dos Institutos Federais.

\section{REFERÊNCIAS}

BARROS, A. J. P.; LEHFELD, N. A. S. Fundamentos de Metodologia: um guia para a iniciação científica. São Paulo: McGraw-Hill, 1986.

BERTI, L. C. et al. Produção científica e formação de recursos humanos na área de Bioquímica em instituições federais do Rio Grande do Sul: fomento estadual. Química Nova, v. 33, n. 3, p. 765-771, 2010.

BRASIL. Decreto $\mathbf{n}^{\circ}$ 19.851. Rio de Janeiro: República dos Estados Unidos do Brasil, 1931. Disponível em: https://www2.camara.leg.br/legin/fed/decret/ 1930-1939/decreto-19851-11-abril-1931-505837-publicacaooriginal-1-pe.html. Acesso em: 27 set. 2019.

BRASIL. Decreto no 5.707, de 23 de fevereiro de 2006. Brasília: Presidência da República, 2006. Disponível em: http://www.planalto.gov.br/ccivil_03/_Ato 2004-2006/2006/Decreto/D5707.htm. Acesso em: 3 maio 2020.

BRASIL. Lei no 11.892, de 29 de dezembro de 2008. Brasília: Presidência da República, 2008. Disponível em: http://www.planalto.gov.br/ccivil_03/_Ato 2007-2010/2008/Lei/L11892.htm. Acesso em: 5 maio 2020.

BRASIL. Plano Nacional pelo Desenvolvimento da Educação (PNDE). Brasília: Ministério da Educação, 2007. Disponível em: https://www.todospela educacao.org.br/conteudo/saiba-o-que-e-e-como-funciona-o-plano-de-desen volvimento-da-educacao/. Acesso em: 4 maio 2020.

DEMO, P. A Nova LDB: ranços e avanços. 3. ed. Campinas: Papirus, 1997.

FERNANDES, F. C. M. Gestão dos Institutos Federais: O Desafio do Centenário da Rede Federal de Educação Profissional e Tecnológica. Holos, Fortaleza, a. 25, v. 2, p. 3-9, 2009. 
FÓRUM DE PRÓ-REITORES DE EXTENSÃO DAS UNIVERSIDADES PÚBLICAS BRASILEIRAS (FORPROEX). Política Nacional de Extensão Universitária. Manaus, 2012. Disponível em: http://www.renex.org.br/docu mentos/2012-07-13-Politica-Nacional-de-Extensao.pdf. Acesso em: 10 out. 2017.

FUJITA, M. S. L. Aspectos evolutivos das bibliotecas universitárias em ambiente digital na perspectiva da rede de bibliotecas da UNESP.

Informação \& Sociedade, João Pessoa, v. 15, n. 2, p. 97-112, jul./dez. 2005.

GALIAZZI, M. C. et al. Objetivos das atividades experimentais no ensino médio: a pesquisa coletiva como modo de formação de professores de ciências. Ciência e Educação, v. 7, n. 2, p. 249-263, 2001.

GIL, A. C. Como elaborar projetos de pesquisa. 4. ed. São Paulo: Atlas, 2002.

JACOBS, D. Demystification of bibliometrics, scientometrics, informetrics and webometrics. In: DIS ANNUAL CONFERENCE, 11., 2010. Conferences [...]. Richardsbay: University of Zululand, 2010. Disponível em: https://www.rese archgate.net/publication/266877235_Demystification_of_Bibliometrics_Scient ometrics_Informetrics_and_Webometrics. Acesso em: 6 jun. 2017.

KUNZE, N. C.; CONCIANI, W. Ensino, pesquisa e extensão: uma relação possível a favor da moradia. In: MINISTÉRIO DA EDUCAÇÃO (MEC).

Cadernos Temáticos. v. 14. Brasília: MEC, 2007. p. 23-30.

MEADOWS, A. J. A comunicação científica. Brasília: Briquet de Lemos, 1999.

MINISTÉRIO DA EDUCAÇÃO (MEC). Um novo modelo em Educação Profissional e Tecnológica: concepções e diretrizes. Brasília: Institutos Federais, 2010. Disponível em: http://portal.mec.gov.br/index.php?option= com_docman\&view=download\&alias=6691-if-concepcaoediretrizes\&category slug =setembro-2010pdf\&ltemid= 30192. Acesso em: 21 out. 2017.

MORAES FILHO, W. B.; SILVEIRA, H. E. Extensão na formação profissional: desafios e possibilidades. Uberlândia: EDUFU, 2011. Disponível em: https://curricularizacaodaextensao.ifsc.edu.br/files/2016/06/5 _Extensao_na_Formacao_Profissional_Desafios_e_Possibilidades.pdf. Acesso em: 10 out. 2017. 
OKUBO, Y. Bibliometric Indicators and analysis of reaserchsytems: methods and examples. Paris: OECD, 1997.

Pacheco, R. C. \& Kern, V. M. (2001). Transparência e gestão do conhecimento por meio de um banco de teses e dissertações: a experiência do PPGEP/UFSC. Ciência da Informação, Brasília, 30(3), 64-72.

REDE FEDERAL. Instituições. Brasília: MEC, 2016. Disponível em: http://rede federal.mec.gov.br/instituicoes. Acesso em: 5 maio 2020.

SANTOS, R. N. M.; KOBASHI, N. Y. Bibliometria, Cientometria, Infometria: conceitos e aplicações. Tendências da Pesquisa Brasileira em Ciência da Informação, Brasília, v. 2, n. 1, p. 155-172, jan./dez. 2009.

SAVIANI, D. Tendências e correntes da educação no Brasil. In: MENDES, D. T. (coord.). Filosofia da educação brasileira. 3 ed. Rio de Janeiro:

Civilização Brasileira, 1987. p. 19-47.

TARGINO, M. G.; GARCIA, J. C. R. Ciência brasileira na base de dados do Institut for Scientific Information (ISI). Ciência da Informação, Brasília, v. 29, n. 1, p. 103-107, jan./abr. 2000. 